\title{
Conformational conversion and prion disease
}

\section{Liang Shen and Hong-Fang Ji}

Because of mechanistic similarities between prion propagation in mammals and fungi, Tuite and Serio recently proposed (The prion hypothesis: from biological anomaly to basic regulatory mechanism. Nature Rev. Mol. Cell Biol. 11, 823-833 (2010)) $)^{1}$ that similarly to fungal prions, which are thought to act as phenotype regulators, prions in mammals should be considered as a basic regulatory mechanism instead of a biological anomaly. However, by considering the behaviour of prions, we argue that the fact that mammalian and fungal prions use a similar mechanism of conformational conversion is not enough to suggest that they are not just infectious agents.

Conformational conversion of a protein from an $\alpha$-helix to a $\beta$-strand is usually associated with a major change in the tertiary structure, which may alter its physiological function and even be implicated in severe diseases. Prion diseases in mammals are one such example; they are caused by the conformational conversion of normal cellular prion protein $\left(\mathrm{PrP}^{\mathrm{C}}\right)$ into an abnormal isoform $\left(\mathrm{PrP}^{\mathrm{Sc}}\right)^{2,3}$. Some fungal proteins can, like prions, also exist in a range of stable conformations and transition between these states under physiological conditions $s^{4}$; thus, this type of protein is known as a fungal prion.

First, the conformational conversions of $\mathrm{PrP}^{\mathrm{C}}$ to $\mathrm{PrP}^{\mathrm{Sc}}$ in mammals may result in two outcomes: loss of function of $\mathrm{PrP}^{\mathrm{C}}$ and/or gain of toxicity of $\mathrm{PrP}^{\mathrm{Sc}}$. If $\mathrm{PrP}^{\mathrm{C}}$ plays an important part in the regulatory pathways that control cellular phenotypes, similarly to fungal prions, loss of its function as a result of conversion to $\mathrm{PrP}^{\mathrm{Sc}}$ should lead to the development of neuropathological and phenotypic alterations that are similar to those seen in mammals with prion diseases. However, PrP-knockout mice, in which the gene encoding PrP has been deleted, do not develop an overt phenotype other than resistance to prion diseases ${ }^{5-7}$. Thus, it seems unlikely that prion pathogenesis is simply due to a loss of $\mathrm{PrP}^{\mathrm{C}}$ physiological function.

In contrast to loss of function of $\mathrm{PrP}^{\mathrm{C}}$, many studies suggest that toxic gain of function of $\mathrm{PrP}^{\mathrm{Sc}}$ gives rise to the pathogenic features of prion diseases ${ }^{8-10}$. It has been proven that the accumulation of $\mathrm{PrP}^{\mathrm{Sc}}$ is linked to apoptotic cell death in animal models and in humans ${ }^{8}$, and a $\operatorname{PrP}$ peptide $\left(\mathrm{PrP}_{106-126}\right)$ has been shown to be neurotoxic to hippocampal cultures, mixed cerebellar cultures and primary neuronal cultures ${ }^{9,10}$. Some attempts to determine the infectious properties of aggregates produced in vitro from recombinant $\mathrm{PrP}$ found that $\mathrm{PrP}^{\mathrm{Sc}}$ infectivity was obtained de novo from recombinant mouse $\operatorname{PrP}^{\mathrm{C}}\left(\mathrm{PrP}_{89-230}\right)$, as shown by transmission studies to transgenic mice $\operatorname{PrP}^{\mathrm{C}}\left(\operatorname{PrP}_{89-231}\right)^{11}$. More recently, recombinant $\operatorname{PrP}^{\mathrm{C}}$ converted into a cross- $\beta$-sheet amyloid was proven to induce prion diseases in hamsters ${ }^{12}$. Unlike mammalian prions, the conformational conversion of fungal prions does not cause diseases but instead modifies the functions of their protein determinants in a self-sustaining way ${ }^{1}$, implying that no toxic products are generated in this process. In addition, the conformational conversion does not seem to be specific to prions, as proteins that adopt different secondary structures under different conditions have not been shown to be associated with disease $\mathrm{e}^{13}$. This indicates that conformational conversion is not intrinsically relevant to the occurrence of diseases.

In summary, owing to lack of PrP homologues in fungi, a conclusion on the potential role of mammalian prions cannot be drawn merely based on their mechanistic similarities to fungal prions. More clues regarding the pathogenesis of prion diseases may be obtained from studies on non-mammalian prions ${ }^{14,15}$, as non-mammals also express PrP-encoding genes but do not develop prion diseases.

Liang Shen and Hong-Fang Ji are at the Shandong Provincial Research Center for Bioinformatic Engineering and Technique, Shandong University of Technology, Zibo 255049, China.

Correspondence to Hong-Fang Ji e-mail: jhf@sdut.edu.cn

doi:10.1038/nrm3007-c1

1. Tuite, M. K. \& Serio, T. R. The prion hypothesis: from biological anomaly to basic regulatory mechanism. Nature Rev. Mol. Cell Biol. 11, 823-833 (2010).

2. Prusiner, S. B. Novel proteinaceous infectious particles cause scrapie. Science 216, 136-144 (1982).

3. Aguzzi, A. \& Polymenidou, M. Mammalian prion biology: one century of evolving concepts. Cell 116, 313-327 (2004).

4. Wickner, R. B., Edskes, H. K., Shewmaker, F. \& Nakayashiki, T. Prions of fungi: inherited structures and biological roles. Nature Rev. Microbiol. 5, 611-618 (2007).

5. Büeler H. et al. Normal development and behavior of mice lacking the neuronal cell-surface PrP protein Nature 356, 577-582 (1992).

6. Büeler, H. et al. Mice devoid of PrP are resistant to scrapie, Cell 73, 1339-1347 (1993).

7. Mallucci, G. R. et al. Postnatal knockout of prion protein alters hippocampal CA1 properties, but does not result in neurodegeneration. $E M B O \mathrm{~J} . \mathbf{2 1}$, 202-210 (2002)

8. Gray, F. et al. Neuronal apoptosis in Creutzfeldt-Jakob disease. J. Neuropathol. Exp. Neurol. 58, 321-328 (1999).

9. Piccardo, P. et al. An antibody raised against a conserved sequence of the prion protein recognizes pathological isoforms in human and animal prion diseases, including Creutzfeldt-Jakob disease and bovine spongiform encephalopathy. Am. J. Pathol. 152, 1415-1420 (1998).

10. Brown, D. R., Schmidt, B. \& Kretzschmar, H. A Role of microglia and host protein in neurotoxicity of a prion protein fragment. Nature $380,345-347$ (1996).

11. Legname, G. et al. Synthetic mammalian prions. Science 305, 673-676 (2004).

12. Makarava, N. et al. Recombinant prion protein induces a new transmissible prion disease in wild-type animals. Acta Neuropathol. 119, 177-187 (2010).

13. Andreeva, A. \& Murzin, A. G. Evolution of protein fold in the presence of functional constraints. Curr. Opin. Struct. Biol. 16, 399-408 (2006).

14. Ji, H. F., Zhang, H. Y. \& Chen, L. L. Why are prion diseases precluded by non-mammals? Trends Biochem. Sci. 32, 206-208 (2007).

15. Ji, H. F. \& Zhang, H. Y. $\beta$-sheet constitution of prion proteins. Trends Biochem. Sci. 35, 129-134 (2010).

\section{Acknowledgements}

The authors' work is supported by the National Natural Science Foundation of China (grants 30700113 and 30800184).

Competing interests statement

The authors declare no competing financial interests. 